\title{
SWITCHING REGIMES IN THE TERM STRUCTURE OF INTEREST RATES DURING U.S. POST-WAR: A case for the Lucas proof equilibrium?*
}

\author{
Jesús Vázquez ${ }^{\dagger}$ \\ Universidad del País Vasco
}

March 2003

\begin{abstract}
Farmer (1991) suggests that in a model in which there are multiple rational expectations (RE) equilibria agents may find it useful to coordinate their expectations in a unique RE equilibrium which is immune to the Lucas Critique. In this paper, we evaluate Lucas proof (LP) equilibrium performance in the context of the term structure of interest rates model by using post-war US data. Estimation results show that LP equilibrium exhibits some important features of the data that are not reproduced by the fundamental equilibrium. For instance, the short rate behaves as a random walk in a regime characterized by low conditional volatility, whereas the term spread Granger-causes changes in the short-rate in periods characterized by high conditional volatility.
\end{abstract}

Key words: Lucas proof, term structure, switching-regimes JEL classification numbers: C32, E43

${ }^{*}$ I am grateful for comments and suggestions from participants at seminars at IRES (University Catholic of Louvain), Universidad del País Vasco, XXVII Simposio de Análisis Económico and X Foro de Finanzas. Financial support from Ministerio de Ciencia y Tecnología, Gobierno Vasco and Universidad del País Vasco (Spain) through projects BEC2000-1393, PI-1999-131 and 9/UPV00035.321-13511/2001, respectively, is gratefully acknowledged.

${ }^{\dagger}$ Correspondence to: Jesús Vázquez, Dpto. Fundamentos del Análisis Económico II, Universidad del País Vasco, Av. Lehendakari Aguirre 83, 48015 Bilbao, Spain. Phone: (34) 94-601-3779, Fax: (34) 94-601-3774, e-mail: jepvapej@bs.ehu.es 


\section{INTRODUCTION}

Farmer (1991) proposes immunity to the Lucas Critique (Lucas (1976)) as a selection criterion in models with multiple rational expectations (RE) equilibria. The idea underlying his paper is that in a model in which there are multiple equilibria agents may find it useful to coordinate in a unique RE equilibrium. This equilibrium can be supported by a selffulfilling forecast rule having the property of being independent of the parameters characterizing the probability distribution of the fundamentals of the economy. In particular, the rule is independent of the parameters governing the process of economic policy. In other words, Farmer's hypothesis is that the Lucas Critique may not apply in some contexts because agents may coordinate their expectations in the Lucas proof (LP) RE equilibrium. ${ }^{1}$

The aim of this paper is to evaluate the performance of the LP equilibrium in the context of the term structure model of interest rate. ${ }^{2}$ Why do we choose this context? Beginning with Mankiw and Miron (1986), many economists have found that the predictive content of the long-short term spread for changes in the short rate have changed substantially over time. ${ }^{3}$ Thus, it is likely that LP equilibrium performs well in this context.

We argue that one can distinguish two types of periods during US postwar. On the one hand, there are periods where the short-term rate behaves as a random walk and the term spread has no predictive content for changes in the short rate. Roughly speaking, these periods are also characterized by relatively low, stable interest rates and inflation. Economists have argued that the near random walk behavior of US short rates is due to US Fed actions for interest rate smoothing. ${ }^{4}$ A possible explanation for the interest rate smoothing policy in a context of low, stable interest rates is that the Fed may have no reason to affect the level of interest rates. In this

\footnotetext{
${ }^{1}$ Farmer (1991) suggests immunity to the Lucas Critique as a selection criterion in models with multiple non-exploding equilibria. Moreover, as Farmer (1992) points out, evidence against the Lucas Critique should not be viewed as evidence against the RE hypothesis, although it is evidence against the so called feedforward view of expectations.

${ }^{2}$ There some papers in the literature testing the Lucas Critique. For instance, Favero and Hendry (1992) tests the Lucas Critique in the context of US money demand. Moreover, Vázquez (2002) tests the Lucas Critique using data from four hyperinflationary episodes.

${ }^{3}$ Many more recent papers (Hamilton (1988), Sola and Driffill (1994), Evans and Lewis (1995), Ang and Bekaert (2002), among others) have shown evidence of (frequent) regime switches in the term structure of US interest rates. Moreover, by allowing the possibility of regime switches Hamilton (1988) and Sola and Driffill (1994) have shown that the RE model of the term structure is not rejected by the data.

${ }^{4}$ As pointed out by McCallum (1994), there is no general consensus on why US Fed follows an interest rate smoothing policy. However, the general view is that the US Fed in fact employed such a policy during the post-war period.
} 
scenario, monetary policy would only aim at keeping the changes in the short-term rate stable and unpredictable. Stable changes in the short-term rate would help macroeconomic stability whereas unpredictable changes in the short rate would allow Fed money market interventions to be anonymous; thus, movements in the short-term rate would reflect the degree of liquidity shortage to money market participants.

On the other hand, there are periods where the short-term rate is still persistent (i.e., the short rate follows a unit root process) but the term spread has some ability to predict short rate changes. These periods are characterized by high, volatile interest rates and inflation. McCallum (1994) argues that one reason for a positive relationship between changes in the short rate and term spread may be that the US Fed tends to tighten monetary policy when the term spread is large, signalling inflationary tensions. ${ }^{5}$

These considerations suggest that the scale of the response of the short rate depends on the level of the term spread. Thus, the response is small and non-significant when the term spread is low, stable and becomes positive when the spread is high, volatile. This paper shows that all these features emerge when estimating a bivariate Markov switching VAR model using postwar US interest rate data from the long end of the maturity spectrum.

Our approach for evaluating the performance of LP equilibrium can be described as follows. First, we consider a bivariate Markov regime switching VAR model as a benchmark model to evaluate the performance of alternative RE equilibria. Ang and Bekaert (2002) have shown that this benchmark model performs well both in forecasting interest rates and in replicating short rate non-linearities found in non-parametric studies (for instance, AïtSahalia (1996a,b)). Moreover, we show that this benchmark model displays the interest rate dynamics obtained estimating an unrestricted four-variable Markov switching VAR model that includes the short-long term spread, the short rate, the output gap and inflation. In sum, the benchmark model can be viewed as a parsimonious yet adequate characterization of the joint dynamics of the long and short-term rates. Second, it is shown formally that the LP and the fundamental equilibrium solutions fit into the benchmark model under different sets of parameter restrictions. Finally, we evaluate the

\footnotetext{
${ }^{5}$ As pointed out by McCallum (1994), in actual practice the US Fed uses other predictor variables instead of the term spread in order to adjust monetary policy when inflationary tensions and recessions are foreseen. But to the extent that these indicators and the spread are closely related (as shown by Mishkin (1990) and Estrella and Mishkin (1997), among others, the spread is a good indicator of expected changes in inflation and economic activity), analysis of interest rate policy responses based on the term spread makes sense. In section 2, we argue that the process assumed for the short-term rate can be viewed as a particular version of the Taylor rule (see Taylor (1993)).
} 
performance of the LP and the fundamental equilibria in order to replicate the features exhibited by the benchmark model.

The estimation results show that the parameter restrictions imposed by the LP equilibrium in the benchmark model are rejected when using a likelihood ratio test or Akaike information criterion (AIC). However, using Schwarz (SIC) or Hannan-Quinn (HQ) model selection criteria that penalize over-parametrizations, the LP equilibrium is chosen instead of the benchmark model. More important, the estimation results show that the LP equilibrium shares most of the relevant features found in the data by estimating the benchmark model. For instance, the short rate behaves as a random walk in a regime characterized by low conditional volatility, whereas the changes in the short-rate are also determined by the term spread in periods characterized by high conditional volatility. Furthermore, the term spread is more persistent in a regime characterized by low conditional volatility than in a regime featuring high conditional volatility.

The estimation results also show that the fundamental equilibrium is not chosen by any model selection criteria considered. Moreover, the fundamental equilibrium does not reproduce many relevant features characterized by the benchmark model and the LP equilibrium.

The remainder of the paper is organized as follows. Section 2 derives the different sets of parameter restrictions imposed by the LP and the fundamental equilibria, respectively, on the benchmark model. Section 3 shows the empirical results and evaluates the performance of the two alternative equilibria to reproduce the features of the term structure of interest rates characterized by the benchmark model. Section 4 concludes.

\section{THE BENCHMARK MODEL, 'LUCAS PROOF' AND FUNDAMENTAL EQUILIBRIA}

Following Ang and Bekaert (2002) closely, we consider a Markov regime switching first-order VAR model of the first-differences of the short-term rate and the term spread as a benchmark model. A similar model, which includes the short-rate in levels instead of the first differences of the short rate, has proven to perform well in forecasting interest rates and in replicating the non-linearity features displayed by interest rates. Formally, the benchmark model can be written as follows

$$
Y_{t}=\mu\left(s_{t}\right)+A\left(s_{t}\right) Y_{t-1}+\Sigma\left(s_{t}\right)^{1 / 2} \varepsilon_{t}
$$


where $Y_{t}=\left(R_{t}-r_{t}, r_{t}-r_{t-1}\right)^{\prime}$ and $\varepsilon_{t} \sim N(0, I) . R_{t}, r_{t}$ and $R_{t}-r_{t}$ denote the long-term, short-term and the spread term, respectively. The regime variable $s_{t}$ is either 1 or 2 and follows a first-order two-state Markov process with $\operatorname{prob}\left(s_{t}=1 \mid s_{t-1}=1\right)=p$ and $\operatorname{prob}\left(s_{t}=2 \mid s_{t-1}=2\right)=q$. We estimate the Cholesky decomposition $\Phi\left(s_{t}\right)$ of $\Sigma\left(s_{t}\right)$ where $\Sigma\left(s_{t}\right)=\Phi\left(s_{t}\right) \Phi\left(s_{t}\right)^{\prime}$.

As shown by Shiller's (1979) seminal paper, the RE theory of the term structure of interest rates postulates the following relation between a longterm rate and a short-term rate

$$
R_{t}=(1-\delta) \sum_{i=0}^{\infty} \delta^{i} E_{t} r_{t+i}+c,
$$

where $E_{t}$ denotes the conditional expectation operator given the information set, $I_{t}$, available to the economic agents at the beginning of time $t$. $I_{t}$ includes current and past values of all random variables included in the model. $\delta$ denotes the discount factor and $c$ is a constant risk premium. ${ }^{6}$

Given the form of the benchmark model and in order to complete the RE model of term structure, we further assume that the short-term interest rate $r_{t}$ is characterized by the following process

$$
r_{t}-r_{t-1}=\rho_{0}\left(s_{t}\right)+\rho_{1}\left(s_{t}\right)\left(R_{t-1}-r_{t-1}\right)+v_{t},
$$

where $\rho_{1}\left(s_{t}\right)$ is a positive policy reaction parameter reflecting how changes in the short-term interest rate try to narrow the long-short spread. $v_{t}$ is an i.i.d. random variable with mean zero and variance $\sigma_{v}^{2}\left(s_{t}\right)$. $v_{t}$ is included in $I_{t}$ since $r_{t}$ and $s_{t}$ are also included. Parameters $\rho_{0}\left(s_{t}\right), \rho_{1}\left(s_{t}\right)$ and $\sigma_{v}\left(s_{t}\right)$ are assumed to follow a two-state Markov process in order to model a different policy reaction function depending on the foreseen inflationary tensions captured by the term spread. One should expect the short rate to behave as a random walk during periods characterized by low, stable interest rates in which the term spread is also low, stable. Contrariwise, one should also expect the short rate to react positively when the term spread is high, volatile since the high, volatile spread indicates the need for restrictive monetary policy (an increase in the short rate) in order to fight inflation.

Readers familiar with the popular Taylor rule may wonder why we do not consider output gaps and inflation to characterize the short-term rate

\footnotetext{
${ }^{6}$ We have considered the possibility of a regime-dependent risk premium. The estimation results reject this hypothesis for the LP equilibrium, whereas a state-dependent risk premium emerges under the fundamental equilibrium when the discount factor is estimated jointly with the other free parameters. These estimation results are available upon request. In any case, the inclusion of a regime-dependent risk premium does not alter any of the conclusions reached in this paper.
} 
dynamics. However, there are at least three compelling reasons for following the approach suggested in this paper. First, Estrella and Mishkin (1997) have shown robust empirical evidence that the term spread contains useful information concerning market expectations of both future real activity and inflation and that the spread summarizes predictive information that is not captured by the variables entering into a typical Taylor rule. Thus, the parsimonious process assumed for the short-term rate (3) can be viewed as a simple version of the Taylor rule where the term spread summarizes at least relevant predictive information as expected output and inflation. Second, as shown below in Section 3, the simple benchmark model (1) captures well the dynamics of the short rate and the spread obtained estimating a fourvariable Markov switching VAR model that includes the term spread, the first-differences of the short rate, the output gap and inflation. ${ }^{7}$ Finally, Ang and Bekaert (2002) have shown that the benchmark model is flexible enough to replicate the short-term rate non-linearities estimated by Aït-Sahalia using nonparametric econometric techniques.

Taking into account equation (2) to evaluate $E_{t} R_{t+1}$ and subtracting $\delta E_{t} R_{t+1}$ from (2) we obtain

$$
R_{t}=(1-\delta) r_{t}+\delta E_{t} R_{t+1}+c(1-\delta)
$$

Equations (3) and (4) form a bivariate system of difference equations. Using the undetermined coefficient method we begin by writing $R_{t}$ as a linear function of a minimal set of state variables: $r_{t}$, and a constant that is state dependant,

$$
R_{t}=\pi_{0}\left(s_{t}\right)+\pi_{1}\left(s_{t}\right) r_{t} .
$$

By using McCallum's (1983) criterion, we can identify a unique fundamental $\mathrm{RE}$ solution given $\mathrm{by}^{8}$ (see mathematical workings at the end of the manuscript)

$$
\pi_{1}(1)=\pi_{1}(2)=1,
$$

\footnotetext{
${ }^{7}$ In Appendix 2, we also compare the estimation results from the single equation (3) with those obtained from the same equation adding current inflation and the output gap as additional explanatory variables in the direction posited by the Taylor rule. The conclusion is that the results are quantitatively similar for all short-term rate processes considered.

${ }^{8}$ McCallum (1983) suggests the minimum state variable criterion to single out a unique RE equilibrium solution in a context of multiple equilibria with the additional requirement that the solution must be valid for any admissible parameter value of the forcing variable process. In particular, it can be shown that the former equilibrium solution is the unique RE fundamental equilibrium because it is the only one that it is a function of a minimal set of state variables and remains valid for any admissible parameter value of the forcing variable (short-term rate) process. For instance, it is the unique fundamental equilibrium when there is a single state (that is, if $p=1$ ).
} 


$$
\begin{aligned}
& \pi_{0}(1)=\frac{A_{2}[c(1-\delta)+\delta D]+\delta^{2}(1-p) E+c \delta(1-\delta)(1-p)}{A_{1} A_{2}-\delta^{2}(1-p)(1-q)} \\
& \pi_{0}(2)=\frac{c(1-\delta)+\delta\left[(1-q) \pi_{0}(1)+E\right]}{A_{2}}
\end{aligned}
$$

where

$$
\begin{aligned}
A_{1} & =1-\delta\left[p\left(1+\rho_{1}(1)\right)+(1-p) \rho_{1}(2)\right], \\
A_{2} & =1-\delta\left[q\left(1+\rho_{1}(2)\right)+(1-q) \rho_{1}(1)\right], \\
D & =p \rho_{0}(1)+(1-p) \rho_{0}(2), \\
E & =q \rho_{0}(2)+(1-q) \rho_{0}(1) .
\end{aligned}
$$

Given that $\pi_{1}(1)=\pi_{1}(2)=1$, we can then estimate the following restricted bivariate system characterized by the unique fundamental $\mathrm{RE}$ equilibrium that satisfies McCallum's criterion:

$$
\begin{aligned}
R_{t}-r_{t} & =\pi_{0}\left(s_{t}\right)+\theta\left(s_{t}\right) u_{t}, \\
r_{t}-r_{t-1} & =\rho_{0}\left(s_{t}\right)+\rho_{1}\left(s_{t}\right)\left[R_{t-1}-r_{t-1}\right]+v_{t} .
\end{aligned}
$$

Notice that we have augmented the bivariate system that characterizes the fundamental $\mathrm{RE}$ equilibrium with an i.i.d. standard normal variable, $u_{t}$, which may be interpreted as a measurement error, and $\theta_{1}$ and $\theta_{2}$ are positive constants.

In addition to the fundamental RE equilibrium, (7), the term structure model of interest rates, equation (2), exhibits another RE equilibrium solution called the backward solution, given by

$$
R_{t}=\delta^{-1} R_{t-1}+\left(1-\delta^{-1}\right) r_{t-1}+\left(1-\delta^{-1}\right) c+\epsilon_{t}
$$

where $\epsilon_{t}$ is an arbitrary martingale difference with respect to $I_{t-1}$ (that is, $\epsilon_{t}=R_{t}-E_{t-1} R_{t}$ is the rational prediction error). ${ }^{9}$ It must be clear that equation (8) is the equilibrium solution of $R_{t}$ supported by the following forecast rule, which is based on the available information at time $t-1$ :

$$
E_{t-1} R_{t}=\delta^{-1} R_{t-1}+\left(1-\delta^{-1}\right) r_{t-1}+\left(1-\delta^{-1}\right) c .
$$

Notice that the long-term rate equilibrium solution (8) is a LP equilibrium solution because it is supported by a forecast rule which is not dependent on

\footnotetext{
${ }^{9}$ See Broze and Szafarz (1991, chapter 2) for a detailed discussion on the non-uniqueness issue. Moreover, Gutiérrez and Vázquez (2002) provides an analysis of the different dynamic features displayed by alternative $\mathrm{RE}$ in the context of present value models with feedback like the one considered in this paper.
} 
the parameters characterizing the short rate process (i.e., $\rho$ 's). Moreover, the LP equilibrium implies that for reasonable parametrizations of the discount factor (that is, $\delta \approx 1$ ), changes in the short-term rate cannot affect substantially the long-term rate. This result is consistent with the evidence reported by Evans and Marshall (2000) which found that monetary policy shocks have large effects on short rates, with a much smaller effect on long rates.

By substracting $r_{t}$ on both sides of the LP equilibrium solution (8) and using (3), the LP equilibrium can be written as

$$
\begin{aligned}
R_{t}-r_{t}= & \left(1-\delta^{-1}\right) c-\rho_{0}\left(s_{t}\right)+\left[\delta^{-1}-\rho_{1}\left(s_{t}\right)\right]\left(R_{t-1}-r_{t-1}\right) \\
& +\epsilon_{t}-v_{t}
\end{aligned}
$$

The LP equilibrium characterized by equations (9) and (3) and the fundamental equilibrium characterized by system (7) impose a different set of parameter restrictions on the benchmark model (1). The main difference between the two alternative equilibria is that the term spread under the LP equilibrium follows a first-order autoregressive process whereas the term spread under the fundamental equilibrium does not depend on lagged term spread.

The idea that an economy is located in a LP equilibrium when agents face frequent monetary policy regime switches is a controversial one. On the one hand, one may think that a LP equilibrium is likely to be supported when agents face frequent changes in policy regime. So agents may find it useful to choose a self-fulfilling forecast rule which is independent of the parameters describing the process of monetary policy (that is, a forecast rule which is immune to the Lucas Critique) as a way of hedging against unanticipated policy regime switches. On the other hand, one could argue that frequent monetary policy changes can reduce the likelihood of expectations being policy independent. By estimating the benchmark model and the alternative $\mathrm{RE}$ equilibrium solutions we can evaluate and compare the performance of the two alternative equilibria. The next section follows this approach.

\section{ESTIMATION AND EVALUATION OF THE TWO ALTERNATIVE EQUILIBRIA}

The alternative models considered in this paper are estimated using two monthly US Treasury yield series (1-month US Treasury bill rate and the US Treasury 20-year yields) available from January 1950 to July 1992 from 
Salomon Brothers' Analytical Record of Yields and Yield Spreads (1992). ${ }^{10}$ We focus our attention on the long end of the maturity spectrum because, as pointed out by Mankiw and Miron in their conclusions, the analysis of the relation between a short-term rate and the rate for twenty-year bonds is probably more important for macroeconomic policy than the empirical analysis based on interest rate data from the short end of the maturity spectrum. Moreover, the sample covers a large period of time in US post-war where it is plausible that various regime switches have occurred. ${ }^{11}$

The maximum likelihood estimation of the alternative Markov regime switching models considered in this paper follows the procedures suggested by Hamilton (1994, ch. 22).

\subsection{Unrestricted Markov switching VAR model}

Before we estimate and evaluate the alternative bivariate Markov regime switching models, we first estimate a Markov regime switching VAR model that includes the term spread, the first-differences of the short-term rate, the output gap and inflation. Formally,

$$
Z_{t}=\Upsilon\left(s_{t}\right)+B\left(s_{t}\right) Y_{t-1}+\Omega\left(s_{t}\right)^{1 / 2} \xi_{t},
$$

where $Z_{t}=\left(R_{t}-r_{t}, r_{t}-r_{t-1}, \Delta p_{t}, y_{t}\right)^{\prime}$ and $\xi_{t} \sim N(0, I) . \Delta p_{t}$ denotes current inflation and $y_{t}$ is the output gap measured as the percentage deviation of output from its long-run trend. This trend component is obtained by adjusting a quadratic trend to the natural logarithm of output. ${ }^{12}$ We estimate the Cholesky decomposition $\Psi\left(s_{t}\right)$ of $\Omega\left(s_{t}\right)$ where $\Omega\left(s_{t}\right)=\Psi\left(s_{t}\right) \Psi\left(s_{t}\right)^{\prime}$.

\footnotetext{
${ }^{10}$ The 1-month Treasury bill rates are shown on a discount basis whereas the Treasury 20-year yields are shown on a bond yield basis. In order to get the appropriate bond yield associated with the 1-month Treasury bill rate we use the Conversion Table for issues Quoted on a Discount Basis, displayed in Salomon Brothers' Analytical Record of Yields and Yield Spreads. Thus, by adding the appropriate percentage shown in the Conversion Table to the discount yield, we obtain the 1-month Treasury bill rate on a bond yield basis.

${ }^{11}$ Moreover, our choice of the data set is determined by the fact that the treasury 20year yields time series are not available for several years during the nineties. Nevertheless, last decade has been characterized by a smooth evolution of interest rates, so the inclusion of more recent data is not likely to affect the empirical evidence found on switching regimes during the seventies and eightees.

${ }^{12}$ The price level and output are measured by the consumer price index and the industrial production index, respectively. These data were collected from the Social Science Data Collection WebSite at University of California, San Diego (http://ssdc.ucsd.edu/citibase).
} 
Table 1. Estimation results for the unrestricted four-variables VAR model (10)

\begin{tabular}{||lcc||}
\hline \hline & Estimated value & Standard error \\
\hline$\gamma_{1}(1)$ & 0.0752 & 0.0428 \\
$\gamma_{2}(1)$ & -0.0231 & 0.0488 \\
$\gamma_{3}(1)$ & 0.0179 & 0.0161 \\
$\gamma_{4}(1)$ & -0.0056 & 0.1150 \\
$\gamma_{1}(2)$ & 0.2828 & 0.1456 \\
$\gamma_{2}(2)$ & -0.2377 & 0.1515 \\
$\gamma_{3}(2)$ & 0.2046 & 0.0405 \\
$\gamma_{4}(2)$ & -0.3204 & 0.1589 \\
$b_{11}(1)$ & 0.9310 & 0.0303 \\
$b_{12}(1)$ & 0.0158 & 0.0440 \\
$b_{13}(1)$ & 0.0039 & 0.1220 \\
$b_{14}(1)$ & -0.0058 & 0.0041 \\
$b_{21}(1)$ & 0.0375 & 0.0365 \\
$b_{22}(1)$ & -0.0332 & 0.0432 \\
$b_{23}(1)$ & -0.0276 & 0.1788 \\
$b_{24}(1)$ & 0.0062 & 0.0040 \\
$b_{31}(1)$ & 0.0045 & 0.0162 \\
$b_{32}(1)$ & -0.0121 & 0.0314 \\
$b_{33}(1)$ & 0.7332 & 0.1287 \\
$b_{34}(1)$ & 0.0024 & 0.0010 \\
$b_{41}(1)$ & 0.0955 & 0.0813 \\
$b_{42}(1)$ & 0.4047 & 0.1788 \\
$b_{43}(1)$ & -0.1438 & 0.4902 \\
$b_{44}(1)$ & 0.9804 & 0.0144 \\
$b_{11}(2)$ & 0.7814 & 0.0630 \\
$b_{12}(2)$ & 0.0617 & 0.1135 \\
$b_{13}(2)$ & 0.2809 & 0.3047 \\
$b_{14}(2)$ & -0.0496 & 0.0167 \\
$b_{21}(2)$ & 0.1902 & 0.0765 \\
\hline \hline
\end{tabular}


Table 1. (continued)

\begin{tabular}{||ccc||}
\hline \hline & Estimated value & Standard error \\
$b_{22}(2)$ & -0.0299 & 0.1402 \\
$b_{23}(2)$ & -0.2379 & 0.3654 \\
$b_{24}(2)$ & 0.0489 & 0.0180 \\
$b_{31}(2)$ & -0.0152 & 0.0121 \\
$b_{32}(2)$ & 0.0100 & 0.0185 \\
$b_{33}(2)$ & 0.5813 & 0.0746 \\
$b_{34}(2)$ & 0.0034 & 0.0042 \\
$b_{41}(2)$ & 0.1447 & 0.0438 \\
$b_{42}(2)$ & 0.3301 & 0.0559 \\
$b_{43}(2)$ & -0.1277 & 0.2601 \\
$b_{44}(2)$ & 1.0127 & 0.0159 \\
$\psi_{11}(1)$ & 0.2654 & 0.0177 \\
$\psi_{12}(1)$ & -0.2481 & 0.0160 \\
$\psi_{13}(1)$ & 0.0062 & 0.0074 \\
$\psi_{14}(1)$ & -0.0891 & 0.0782 \\
$\psi_{22}(1)$ & 0.0894 & 0.0068 \\
$\psi_{23}(1)$ & 0.0057 & 0.0105 \\
$\psi_{24}(1)$ & 0.2000 & 0.0765 \\
$\psi_{33}(1)$ & 0.0695 & 0.0094 \\
$\psi_{34}(1)$ & -0.0464 & 0.0822 \\
$\psi_{44}(1)$ & 1.1434 & 0.0787 \\
$\psi_{11}(2)$ & 0.9444 & 0.0926 \\
$\psi_{12}(2)$ & -0.9438 & 0.1042 \\
$\psi_{13}(2)$ & -0.0183 & 0.0135 \\
$\psi_{14}(2)$ & -0.0647 & 0.0731 \\
$\psi_{22}(2)$ & 0.4492 & 0.0368 \\
$\psi_{23}(2)$ & 0.0391 & 0.0172 \\
$\psi_{24}(2)$ & 0.2088 & 0.0573 \\
$\psi_{33}(2)$ & 0.2196 & 0.0159 \\
\hline \hline
\end{tabular}


Table 1. (continued)

\begin{tabular}{||ccc||}
\hline \hline & Estimated value & Standard error \\
$\psi_{34}(2)$ & 0.1028 & 0.0521 \\
$\psi_{44}(2)$ & 0.7952 & 0.0580 \\
$p$ & 0.9807 & 0.0064 \\
$q$ & 0.9274 & 0.0181 \\
Mean log-likelihood & 0.8464 & \\
\hline \hline
\end{tabular}

Notes: $\gamma_{i}\left(s_{t}\right)$ denotes a generic element of vector $\Upsilon\left(s_{t}\right), b_{i j}\left(s_{t}\right)$ denotes a generic element of matrix $B\left(s_{t}\right)$ and $\psi_{i j}\left(s_{t}\right)$ denotes a generic element of matrix $\Psi\left(s_{t}\right)^{\prime}$.

The estimation results for (10) are shown in Table 1 . We observe that regime 1 is more persistent than regime 2 since the estimated value of $p$ is significantly larger than $q$. Focusing on the estimates from the first two equations that jointly describe the dynamics of the term spread and the first-differences of the short rate, we see that the short rate behaves as a random walk in the first regime, whereas the changes in the short rate are mainly determined by the spread in the second. More specifically, we observe that the coefficients associated with inflation and the output gap are not significantly different from zero with the exception of the coefficient associated with the output gap in the second equation in the second regime. This coefficient is relatively small (i.e., $b_{24}(2)$ is four times smaller than the coefficient associated with the term spread, $\left.b_{21}(2)\right)$ but significant. Thus, the empirical results suggest a type of dichotomy. Namely, the spread and the changes in the short rate can be analyzed independently of inflation and output gaps without much of loss of generality as is confirmed below. Figure 1 shows the allocation of time periods based on the smoothed probabilities for the first regime using the information over the whole sample of size $T$ (i.e., $\operatorname{prob}\left[s_{t}=1 \mid I_{T}\right]$ ).

\subsection{Estimation results for the benchmark model}

Table 2 shows the estimation results for the benchmark model (1). These estimation results are quantitatively similar to those found previously when estimating (10). These dynamics can be summarized as follows. First, there are two alternative regimes one of which (say regime 1) is more persistent than the other (regime 2). Thus, the estimated value of $p$ is significantly larger than $q$. Moreover, the estimated values are similar to those obtained estimating the four-variable Markov regime switching model (10). Furthermore, the persistence of the system in each regime can be 


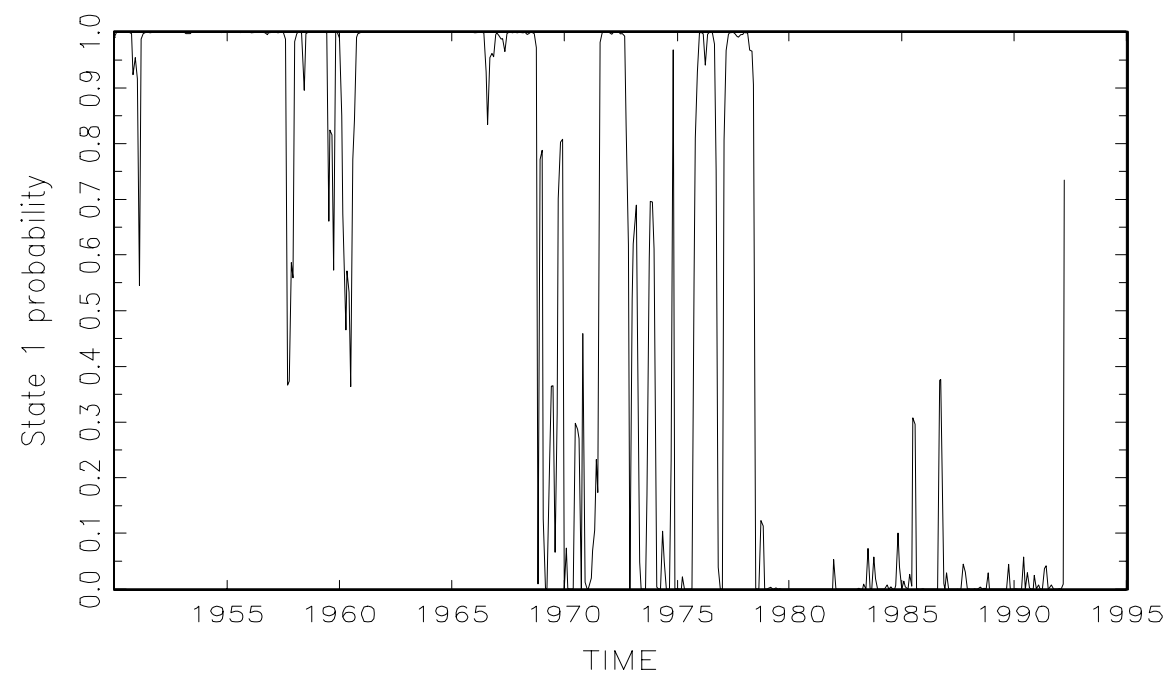

Figure 1: Unrestricted VAR model (10)

measured through the moduli of the eigenvalues for the companion matrices $A(1)$ (0.9491 and -0.0192) and $A(2)$ (0.8444 and -0.0436), showing that the first regime is clearly more persistent. Second, the conditional covariances are larger in the second regime than in the first. Moreover, the sample correlation between the rate of inflation and the second regime smoothed probabilities is found to be 0.49 . This value implies that the highly conditional volatility regime is associated with current inflation although, as pointed out by Evans and Lewis (1995) and Ang and Bekaert (2002), the fit between inflation and the highly conditional volatility regime is not perfect. 
Table 2. Estimation results for the benchmark model (spread term and first differences of the short rate)

\begin{tabular}{|c|c|c|c|}
\hline & & Estimated value & Standard error \\
\hline & $\mu_{1}(1)$ & 0.0513 & 0.0317 \\
\hline & $\mu_{2}(1)$ & 0.0043 & 0.0301 \\
\hline & $\mu_{1}(2)$ & 0.3149 & 0.1431 \\
\hline & $\mu_{2}(2)$ & -0.2598 & 0.1719 \\
\hline & $a_{11}(1)$ & 0.9489 & 0.0179 \\
\hline & $a_{12}(1)$ & 0.0124 & 0.0326 \\
\hline & $a_{21}(1)$ & 0.0160 & 0.0176 \\
\hline & $a_{22}(1)$ & -0.0190 & 0.0399 \\
\hline & $a_{11}(2)$ & 0.8337 & 0.0588 \\
\hline & $a_{12}(2)$ & 0.0667 & 0.1340 \\
\hline & $a_{21}(2)$ & 0.1413 & 0.0709 \\
\hline & $a_{22}(2)$ & -0.0329 & 0.1631 \\
\hline & $\phi_{11}(1)$ & 0.2436 & 0.0382 \\
\hline & $\phi_{12}(1)$ & -0.2240 & 0.0377 \\
\hline & $\phi_{22}(1)$ & 0.0961 & 0.0061 \\
\hline & $\phi_{11}(2)$ & 1.0318 & 0.0909 \\
\hline & $\phi_{12}(2)$ & -1.0297 & 0.1079 \\
\hline & $\phi_{22}(2)$ & 0.4736 & 0.0395 \\
\hline & $p$ & 0.9868 & 0.0049 \\
\hline & $q$ & 0.8932 & 0.0114 \\
\hline Mean & log-likelihood & -0.2956 & \\
\hline & $A I C$ & 341.545 & \\
\hline & $S I C$ & 550.921 & \\
\hline & $H Q$ & 374.748 & \\
\hline
\end{tabular}

Notes for Tables 1-3: Heteroskedastic-consistent standard errors are shown. The Akaike, Schwarz and Hannan-Quinn model selection criteria are computed as $A I C=-2 L+2 n, S I C=-2 L+2 n \ln (T)$ and $H Q=-2 L+2 n \ln (\ln (T))$, respectively, where $L$ is the maximum value of the Gaussian log-likelihood function, $n$ is the number of estimated parameters and $T=510$ is the number of observations.

\subsection{A comparison with Ang and Bekaert's results}

In order to compare our estimation results with those from Ang and Bekaert (2002), the benchmark model is estimated by including the short-rate in levels instead of the first-difference of the short-term rate. Moreover, the 
benchmark model is also estimated by allowing for time-varying transition probabilities. These estimation results are displayed in the Appendix 1: Tables A1-A.3. The estimation results show that the short rate process is also characterized by a unit-root in the second regime when the short rate responds to changes in the spread. This result supports the choice of considering the first-differences of the short rate instead of the level of the short rate when estimating the benchmark model.

Although our data set is different from the one considered by Ang and Bekaert (2002), ${ }^{13}$ our estimation results are to some extent similar to those found by them using US data, with two main exceptions. First, considering time-varying transition probabilities does not improve the fit of the benchmark model for our sample. Second, for our sample, we reject the hypothesis that both short rate and spread Granger-cause each other for the low conditional volatility regime (regime 1), while also rejecting the hypothesis that the spread does not Granger-cause the short rate for the high conditional volatility regime (regime 2). However, Ang and Bekaert (2002) obtained quite different conclusions. ${ }^{14}$

One possible explanation for these different results is that our sample is rather different from the one considered by Ang and Bekaert (2002) since our sample period includes the fifties and the sixties (almost half of the sample) that were characterized by lower and more stable interest rates and spreads than those observed in the rest of the sample. Table A.4, displayed in the appendix, shows a summary statistics of data. Many of the statistics shown in this table are quite different from the ones reported by Ang and Bekaert's Table 1.

Moreover, the estimation of the benchmark model including the short rate in levels and time-varying transition probabilities allows us to analyze the robustness of the results by imposing the unit root restriction on the short rate and considering constant transition probabilities when estimating the benchmark model. Since the estimation results in Table 2 are quantitatively

\footnotetext{
${ }^{13}$ Ang and Bekaert (2002) work with monthly observations on 3-month short rates and 5-year long rates of zero coupons from the US, Germany and UK from January 1972 to August 1996.

${ }^{14}$ In our view their empirical results are at odds with their economic interpretation (see Ang and Bekaert (2002, p.1257). For instance, they claim that the first regime corresponds to periods where the short rate behaves as a random walk. It must be the case, therefore, that the term spread does not Granger-cause the short rate during the first regime; however, they obtain evidence in the opposite direction. Contrariwise, in the second regime where the spread is large, volatile, one should expect the spread can Granger-cause the short rates since short rates react positively to the term spread in order to fight inflation under this regime, but they have evidence that once again contradicts this intuition.
} 
similar to those in Tables A.1-A.3, we will impose the unit root restriction in both regimes and the assumption of constant transition probabilities from now on. ${ }^{15}$

\subsection{Evaluation of the LP equilibrium}

Table 3 shows the estimation results for the LP equilibrium described by the bivariate system (9)-(3). ${ }^{16}$ The estimation results from this equilibrium share several features displayed by the benchmark model and the Markov switching four-variable VAR model. Namely, regime 1 is more persistent than regime 2. Thus, the estimated value of $p$ is larger than $q$ and they are similar to the estimated values found in the benchmark model. Moreover, the term spread is more persistent in the first regime than in the second (that is, $\left[\delta^{-1}-\rho_{1}(1)\right]$ ) is larger than $\left.\left[\delta^{-1}-\rho_{1}(2)\right]\right)$. Second, the conditional covariances in the second regime are larger than those found in the first. Third, the first-difference of the short-term rate is a purely random noise in the first regime under the benchmark model and the LP equilibrium since $a_{21}(1), a_{22}(1)$ and $\rho_{1}(1)$ are not significant, whereas the short-term rate positively reacts with changes in the term spread in the second regime under the two models $\left(a_{21}(2)\right.$ and $\rho_{1}(2)$ are significant at standard confidence levels). Fourth, a non-significant risk premium, $c$, together with a non-significant $\rho_{0}(1)$ is consistent with $\mu_{1}(1)$ not being significant. Moreover, a significant $\rho_{0}(2)$ is consistent with $\mu_{1}(2)$ being significant.

\footnotetext{
${ }^{15}$ Further, standard integration and cointegration tests (see Table A.5 in the appendix) do not reject the hypotheses that the short rate and the long rate follow $\mathrm{I}(1)$ processes and that the two rates are cointegrated, i.e., the term spread is stationary.

${ }^{16}$ In the estimation of the LP and fundamental equilibria, the discount factor $\delta$ is fixed at 0.9958428 . This value is consistent with the sample mean of the short-term rate.
} 
Table 3. Estimation results for the LP equilibrium

\begin{tabular}{||ccc||}
\hline \hline & Estimated value & Standard error \\
\hline$\rho_{0}(1)$ & -0.0168 & 0.0334 \\
$\rho_{0}(2)$ & -0.3210 & 0.1432 \\
$\rho_{1}(1)$ & 0.0371 & 0.0201 \\
$\rho_{1}(2)$ & 0.1827 & 0.0614 \\
$c$ & 0.0094 & 0.0076 \\
$\phi_{11}(1)$ & 0.0934 & 0.0055 \\
$\phi_{12}(1)$ & 0.0601 & 0.0203 \\
$\phi_{22}(1)$ & 0.2332 & 0.0225 \\
$\phi_{11}(2)$ & 0.4662 & 0.0307 \\
$\phi_{12}(2)$ & 0.4629 & 0.1131 \\
$\phi_{22}(2)$ & 0.9974 & 0.0832 \\
$p$ & 0.9836 & 0.0046 \\
$q$ & 0.8979 & 0.0111 \\
Mean $\log -$ likelihood & -0.3197 & \\
AIC & 352.127 & \\
SIC & 488.221 & \\
$H Q$ & 373.709 & \\
\hline \hline
\end{tabular}

One can test the parameter restrictions imposed by the LP equilibrium on the benchmark model using a likelihood ratio test statistic that in this case is distributed as $\chi^{2}(7)$. This statistic takes the value 24.58 , which implies that the parameter restrictions imposed by the LP equilibrium on the benchmark model are rejected by the data at any standard significance level. A similar conclusion is reached using Akaike information criterion (AIC). However, when using Schwarz (SIC) or Hannan-Quinn (HQ) information criteria the LP equilibrium is selected instead of the benchmark model. The reason for these results is that SIC and HQ selection criteria penalizes the inclusion of additional free parameters in the model more than AIC and the likelihood ratio test. 
Table 4. Estimation results for the fundamental equilibrium

\begin{tabular}{|c|c|c|c|}
\hline & & Estimated Value & Standard Error \\
\hline & $\rho_{0}(1)$ & -0.0901 & 0.0316 \\
\hline & $\rho_{0}(2)$ & -0.1652 & 0.1696 \\
\hline & $\rho_{1}(1)$ & 0.1184 & 0.0381 \\
\hline & $\rho_{1}(2)$ & 0.1175 & 0.0745 \\
\hline & $\sigma_{v}(1)$ & 0.2521 & 0.0153 \\
\hline & $\sigma_{v}(2)$ & 1.0266 & 0.1015 \\
\hline & $p$ & 0.9945 & 0.0027 \\
\hline & $q$ & 0.9474 & 0.0118 \\
\hline & $c$ & -3.9868 & 4.1031 \\
\hline & $\theta(1)$ & 0.6290 & 0.0452 \\
\hline & $\theta(2)$ & 1.6657 & 0.1269 \\
\hline \multirow[t]{5}{*}{ Mean } & log-likelihood & -2.11233 & \\
\hline & $A I C$ & 2176.577 & \\
\hline & $S I C$ & 2291.734 & \\
\hline & $H Q$ & 2194.838 & \\
\hline & $T$ & 510 & \\
\hline
\end{tabular}

Table 4 shows the estimation results for the fundamental equilibrium described by the bivariate system (7). Any model selection criteria considered (likelihood ratio test, AIC, SIC and HQ) rejects the fundamental equilibrium in favor of the LP equilibrium. The estimation results from this equilibrium share some features displayed by the benchmark model and the LP equilibrium. Thus, regime 1 is more persistent than regime 2 since the estimated value of $p$ is larger than $q$, but the estimates are significantly different from those obtained in the benchmark model and the LP equilibrium. Second, the conditional covariances in the second regime are larger than in the first. However, as shown in Section 2, the term spread does not show any persistence under the fundamental equilibrium since the coefficient associated with $\left(R_{t-1}-r_{t-1}\right)$ for any regime must be zero under this equilibrium by definition. Moreover, estimation results obtained from the fundamental equilibrium differ from those obtained in the benchmark model and the LP equilibrium. Thus, the coefficient associated with the lagged term spread in the short-term rate equation is significant in regime 1 but not in regime 2 . The opposite is true both for the benchmark model and for the LP equilibrium.

Figures 2-4 show the allocation of time periods based on the smoothed probabilities for the first regime for the benchmark model, the LP equilibrium 


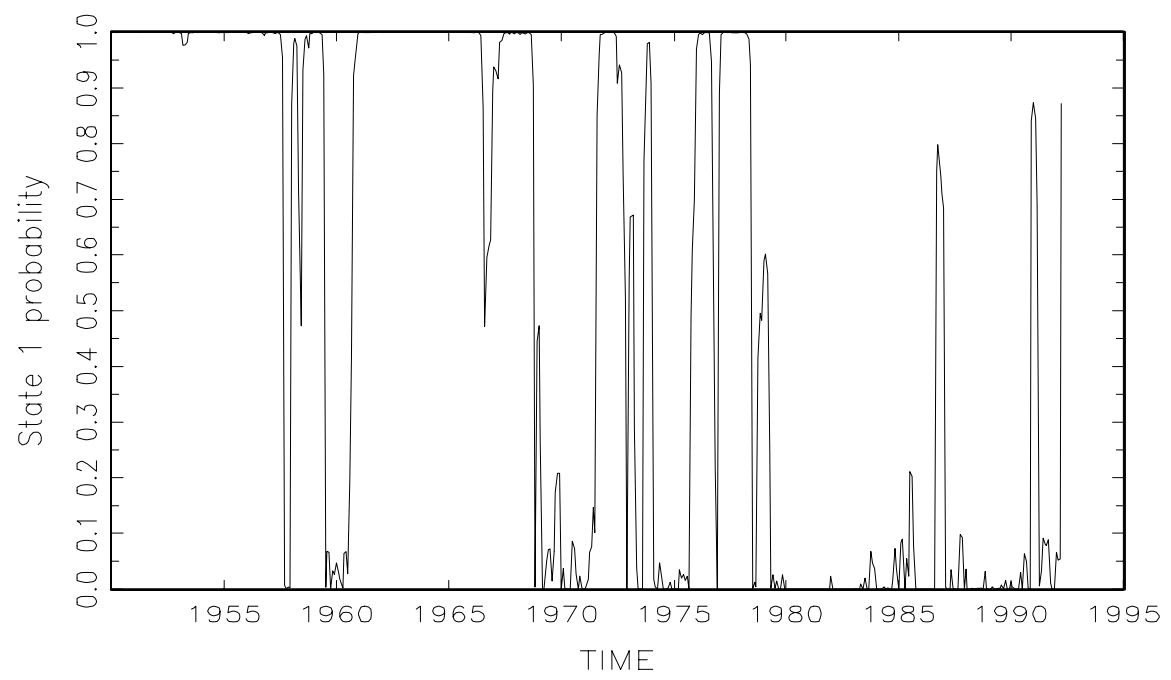

Figure 2: Benchmark model

and the fundamental equilibrium, respectively. We observe that the smoothed probabilities for the unrestricted four-variable model (Fig. 1) are almost identical to those found for the benchmark model (Fig. 2) and the LP equilibrium (Fig. 3). In spite of its simplicity, it is noticeable to observe that the smoothed probabilities associated with the fundamental equilibrium (Fig. 4) do not differ substantially from the ones implied by the other two models. The main differences are concentrated in the seventies and around the 1987 stock market crash. 


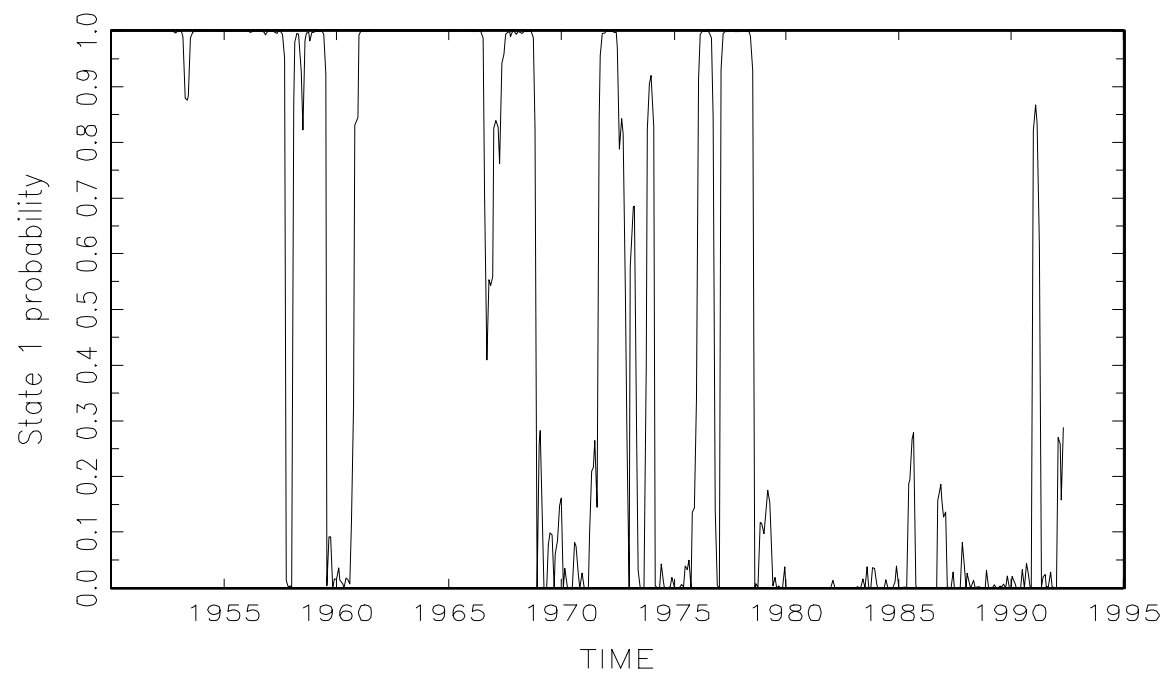

Figure 3: Lucas-proof equilibrium 


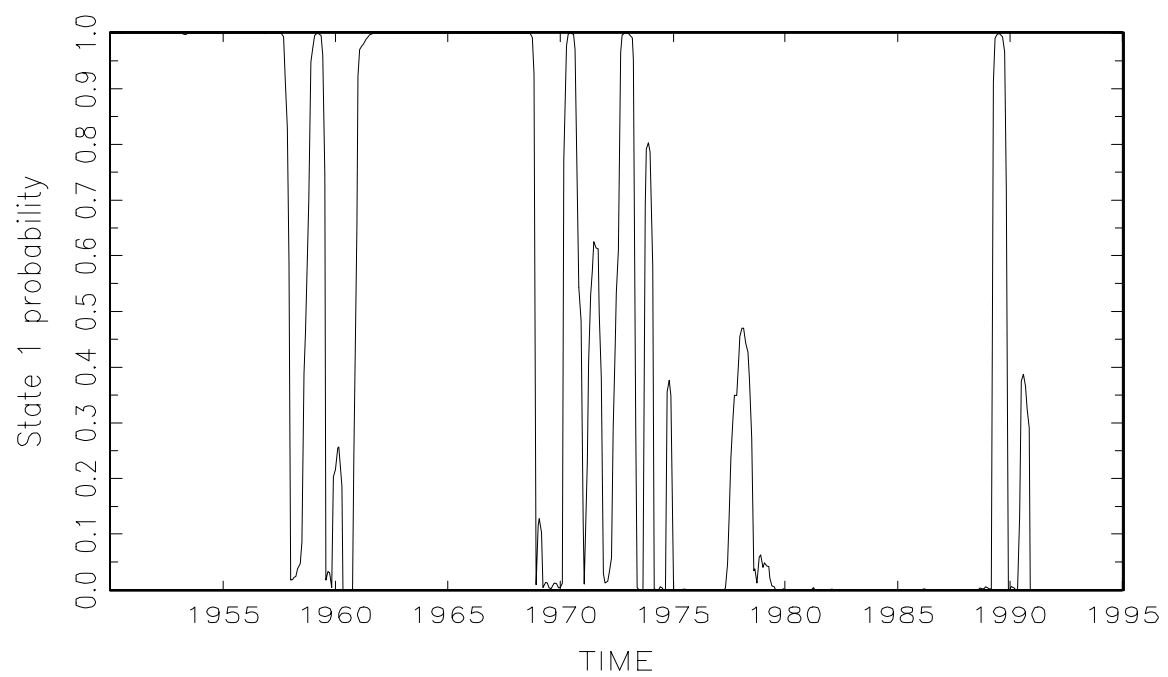

Figure 4: Fundamental equilibrium 


\section{CONCLUSIONS}

There is much literature showing evidence of frequent regime switches in US short-term interest rates. Economists have related these switches to changes in monetary policy. Thus, the smoothing policy of interest rates carried out by US Fed during low inflation periods make the short rate behaves as a random walk. However, when extraordinary shocks occur and inflation and term spread become higher and more volatile, policy makers can switch monetary policy to an alternative regime where the short rate responds positively to large, volatile term spread in order to fight inflation.

In this paper we argue that agents facing frequent policy regime switches may find it useful to coordinate their expectations in a Lucas proof equilibrium as a way of hedging against unanticipated monetary policy regime switches. Using post-war US interest rate data, we evaluate the performance of the Lucas proof equilibrium. Estimation results show that Lucas proof equilibrium exhibits the following important features of the data that are not well reproduced by the fundamental equilibrium. First, the short-term rate behaves as a random walk in a regime characterized by low conditional volatility, whereas the term spread Granger-causes the short-rate in periods characterized by high conditional volatility. Second, the term spread is highly persistent especially in the low conditional volatility regime. Moreover, the result that movements in the short-term rate have negligible effects on long-term rates under the LP equilibrium is consistent with the evidence found by Evans and Marshall (2000) that monetary policy shocks have much smaller effects on long-term rates than on short-term rates. 


\section{APPENDIX 1}

Table A.1. Estimation results for the benchmark model (spread term and short rate in levels)

\begin{tabular}{||ccc||}
\hline \hline & Estimated value & Standard error \\
\hline$\mu_{1}(1)$ & 0.0695 & 0.0394 \\
$\mu_{2}(1)$ & -0.0129 & 0.0420 \\
$\mu_{1}(2)$ & 0.0532 & 0.2712 \\
$\mu_{2}(2)$ & 0.0966 & 0.2797 \\
$a_{11}(1)$ & 0.9488 & 0.0180 \\
$a_{12}(1)$ & -0.0046 & 0.0096 \\
$a_{21}(1)$ & 0.0170 & 0.0181 \\
$a_{22}(1)$ & 1.0040 & 0.0107 \\
$a_{11}(2)$ & 0.8443 & 0.0577 \\
$a_{12}(2)$ & 0.0331 & 0.0343 \\
$a_{21}(2)$ & 0.1150 & 0.0680 \\
$a_{22}(2)$ & 0.9569 & 0.0376 \\
$\phi_{11}(1)$ & 0.2436 & 0.0432 \\
$\phi_{12}(1)$ & -0.2241 & 0.0423 \\
$\phi_{22}(1)$ & 0.0955 & 0.0071 \\
$\phi_{11}(2)$ & 1.0270 & 0.0963 \\
$\phi_{12}(2)$ & -1.0206 & 0.1100 \\
$\phi_{22}(2)$ & 0.4731 & 0.0391 \\
$p$ & 0.9867 & 0.0054 \\
$q$ & 0.8942 & 0.0114 \\
AIC & -0.2913 & \\
SIC & 337.164 & \\
$H Q$ & 546.540 & \\
\hline \hline
\end{tabular}


Table A.2. Estimation results for the benchmark model (spread term and short rate in levels) by allowing time-varying transition probabilities

\begin{tabular}{||ccc||}
\hline \hline & Estimated value & Standard error \\
\hline$\mu_{1}(1)$ & 0.0708 & 0.0401 \\
$\mu_{2}(1)$ & -0.0166 & 0.0469 \\
$\mu_{1}(2)$ & 0.0694 & 0.2868 \\
$\mu_{2}(2)$ & 0.0868 & 0.2970 \\
$a_{11}(1)$ & 0.9477 & 0.0180 \\
$a_{12}(1)$ & -0.0052 & 0.0096 \\
$a_{21}(1)$ & 0.0185 & 0.0208 \\
$a_{22}(1)$ & 1.0054 & 0.0113 \\
$a_{11}(2)$ & 0.8435 & 0.0575 \\
$a_{12}(2)$ & 0.0320 & 0.0358 \\
$a_{21}(2)$ & 0.1150 & 0.0686 \\
$a_{22}(2)$ & 0.9573 & 0.0391 \\
$\phi_{11}(1)$ & 0.2524 & 0.0465 \\
$\phi_{12}(1)$ & -0.2324 & 0.0483 \\
$\phi_{22}(1)$ & 0.0947 & 0.0083 \\
$\phi_{11}(2)$ & 1.0304 & 0.0974 \\
$\phi_{12}(2)$ & -1.0245 & 0.1110 \\
$\phi_{22}(2)$ & 0.4769 & 0.0392 \\
$\gamma_{0}(1)$ & 4.8095 & 1.2405 \\
$\gamma_{0}(2)$ & 1.0836 & 0.6062 \\
$\gamma_{1}(1)$ & 0.0922 & 0.3851 \\
$\gamma_{1}(2)$ & 0.0940 & 0.1056 \\
$\gamma_{2}(1)$ & -0.1418 & 0.1768 \\
$\gamma_{2}(2)$ & 0.1317 & 0.0676 \\
AIC & -0.2884 & \\
$S I C$ & 342.780 & \\
$H Q$ & 594.125 & \\
Mean & 382.639 & \\
\hline \hline
\end{tabular}

Note: $\operatorname{prob}\left(s_{t}=i \mid s_{t-1}=i, I_{t}\right)=\exp \left[\gamma_{0}(i)+\gamma_{1}(i)\left(R_{t-1}-r_{t-1}\right)+\right.$ $\left.\gamma_{2}(i) r_{t-1}\right] /\left[1+\exp \left(\gamma_{0}(i)+\gamma_{1}(i)\left(R_{t-1}-r_{t-1}\right)+\gamma_{2}(i) r_{t-1}\right)\right]$, for $i=1,2$. 
Table A.3. Estimation results for the benchmark model (spread term and first-differences of the short rate) by allowing time-varying transition probabilities

\begin{tabular}{|c|c|c|c|}
\hline & & Estimated value & Standard error \\
\hline & $\overline{\mu_{1}(1)}$ & 0.0508 & 0.0320 \\
\hline & $\mu_{2}(1)$ & 0.0047 & 0.0304 \\
\hline & $\mu_{1}(2)$ & 0.3171 & 0.1462 \\
\hline & $\mu_{2}(2)$ & -0.2617 & 0.1748 \\
\hline & $a_{11}(1)$ & 0.9489 & 0.0183 \\
\hline & $a_{12}(1)$ & 0.0121 & 0.0327 \\
\hline & $a_{21}(1)$ & 0.0159 & 0.0179 \\
\hline & $a_{22}(1)$ & -0.0186 & 0.0342 \\
\hline & $a_{11}(2)$ & 0.8333 & 0.0589 \\
\hline & $a_{12}(2)$ & 0.0668 & 0.1346 \\
\hline & $a_{21}(2)$ & 0.1417 & 0.0710 \\
\hline & $a_{22}(2)$ & -0.0330 & 0.1640 \\
\hline & $\phi_{11}(1)$ & 0.2441 & 0.0426 \\
\hline & $\phi_{12}(1)$ & -0.2245 & 0.0427 \\
\hline & $\phi_{22}(1)$ & 0.0964 & 0.0060 \\
\hline & $\phi_{11}(2)$ & 1.0327 & 0.0917 \\
\hline & $\phi_{12}(2)$ & -1.0307 & 0.1087 \\
\hline & $\phi_{22}(2)$ & 0.4741 & 0.0413 \\
\hline & $\gamma_{0}(1)$ & 4.1270 & 0.4368 \\
\hline & $\gamma_{0}(2)$ & 2.1171 & 0.1783 \\
\hline & $\gamma_{1}(1)$ & 0.1736 & 0.4037 \\
\hline & $\gamma_{1}(2)$ & 0.0042 & 0.0784 \\
\hline & $\gamma_{2}(1)$ & 0.0723 & 0.5243 \\
\hline & $\gamma_{2}(2)$ & -0.0094 & 0.1646 \\
\hline \multirow[t]{4}{*}{ Mean } & log-likelihood & -0.2955 & \\
\hline & $A I C$ & 349.431 & \\
\hline & $S I C$ & 600.683 & \\
\hline & $H Q$ & 389.275 & \\
\hline
\end{tabular}

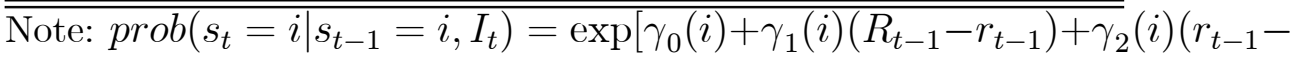
$\left.\left.r_{t-2}\right)\right] /\left[1+\exp \left(\gamma_{0}(i)+\gamma_{1}(i)\left(R_{t-1}-r_{t-1}\right)+\gamma_{2}(i)\left(r_{t-1}-r_{t-2}\right)\right)\right]$, for $i=1,2$. 
Table A.4. Summary of statistics of data

\begin{tabular}{||ccccc||}
\hline \hline & Short rate & Spread & Short rate & Spread \\
\hline Sample Period & $1950: 1-1992: 7$ & $1950: 1-1992: 7$ & $1970: 1-1992: 7$ & $1970: 1-1992: 7$ \\
Mean & 5.0296 & 1.5188 & 6.9897 & 2.0007 \\
Std. deviation & 2.9625 & 1.3334 & 2.5559 & 1.5812 \\
Skewness & 0.9190 & 0.3194 & 1.1254 & -0.3951 \\
Kurtosis & 0.8922 & 0.2231 & 1.3321 & -0.1870 \\
First autoc. & 0.9711 & 0.8800 & 0.9358 & 0.8558 \\
Second autoc. & 0.9468 & 0.8075 & 0.8813 & 0.7673 \\
Third autoc. & 0.9257 & 0.7435 & 0.8310 & 0.6815 \\
Cross-correl. & -0.1497 & & -0.5977 & \\
\hline \hline
\end{tabular}

Table A.5. Phillips-Perron $\mathrm{Z}_{\rho}$ tests

\begin{tabular}{||llll||}
\hline \hline Period & Variable & With Trend & Without Trend \\
\hline Sample & $R_{t}$ & -6.27 & -3.22 \\
1950:1-1992:7 & $r_{t}$ & -21.38 & -11.76 \\
& $\Delta R_{t}$ & -417.02 & -417.05 \\
& $\Delta r_{t}$ & -512.45 & -512.69 \\
& $R_{t}-r_{t}$ & -62.19 & -50.82 \\
\hline \hline
\end{tabular}

Notes: The Phillips-Perron $Z_{\rho}$ statistics are corrected for fourth-order serial correlation. The results are qualitatively similar to those obtained when considering Phillips-Perron $Z_{t_{\rho}}$ and augmented Dickey-Fuller tests, or when considering alternative orders of the serial correlation correction in computing Phillips-Perron statistics. For a sample size of 500 observations, the critical values for the Phillips-Perron $\mathrm{Z}_{\rho}$ test are: with trend: $10 \%,-18.1 ; 5 \%,-21.5 ; 1 \%,-28.9$; without trend: $10 \%,-11.2 ; 5 \%,-14.0 ; 1 \%,-20.5$. A table displaying the critical values for the Phillips-Perron $Z_{\rho}$ test is reported in Fuller (1976, p. 371).

\section{APPENDIX 2}

Table A.6 shows the maximum likelihood estimation results for the following three alternative specifications for the short-term rate process:

$$
\begin{gathered}
r_{t}-r_{t-1}=\rho_{0}\left(s_{t}\right)+\rho_{1}\left(s_{t}\right)\left(R_{t-1}-r_{t-1}\right)+v_{t}, \\
r_{t}-r_{t-1}=\rho_{0}\left(s_{t}\right)+\rho_{1}\left(s_{t}\right)\left(R_{t-1}-r_{t-1}\right)+\rho_{2}\left(s_{t}\right) \Delta p_{t}+v_{t}, \\
r_{t}-r_{t-1}=\rho_{0}\left(s_{t}\right)+\rho_{1}\left(s_{t}\right)\left(R_{t-1}-r_{t-1}\right)+\rho_{2}\left(s_{t}\right) \Delta p_{t}+\rho_{3}\left(s_{t}\right) y_{t}+v_{t} .
\end{gathered}
$$


Table A.6. Estimation of alternative short-term rate processes

\begin{tabular}{||llll||}
\hline \hline$T=511$ & Equation (3) & Equation (11) & Equation (12) \\
\hline$\rho_{0}(1)$ & 0.0291 & 0.0145 & -0.0017 \\
$\rho_{0}(2)$ & $(0.0271)$ & $(0.0317)$ & $(0.0401)$ \\
& -0.3693 & -0.6821 & -0.7097 \\
$\rho_{1}(1)$ & $(0.1541)$ & $(0.2433)$ & $(0.2447)$ \\
& 0.0003 & -0.0013 & 0.0152 \\
$\rho_{1}(2)$ & $(0.0153)$ & $(0.0154)$ & $(0.0192)$ \\
& 0.2086 & 0.2535 & 0.3379 \\
$\rho_{2}(1)$ & $(0.0677)$ & $(0.0740)$ & $(0.0795)$ \\
& & 0.1018 & 0.0270 \\
$\rho_{2}(2)$ & & $(0.0775)$ & $(0.0988)$ \\
& & 0.6538 & 0.5302 \\
$\rho_{3}(1)$ & & $(0.4094)$ & $(0.4068)$ \\
& & & 0.0064 \\
$\rho_{3}(2)$ & & & $(0.0035)$ \\
$\sigma_{v}(1)$ & & & 0.0726 \\
& & & $(0.0250)$ \\
$\sigma_{v}(2)$ & 0.2243 & 0.2287 & 0.2286 \\
& $(0.0124)$ & $(0.0134)$ & $(0.0180)$ \\
$p$ & 1.2734 & 1.2808 & 1.2360 \\
& $(0.0910)$ & $(0.0971)$ & $(0.1059)$ \\
$q$ & 0.9763 & 0.9761 & 0.9765 \\
Meanlog-likelihood & -0.5422 & -0.5375 & $(0.0091)$ \\
\hline \hline
\end{tabular}

Note: Standard errors in parentheses.

The estimation results clearly show that for the first regime none of three variables considered help to explain changes in the short-term rate. Therefore, these estimation results confirm the hypothesis that the shortterm interest rate follows a random walk in the first regime. For the second regime, the term spread and the output gap explain the changes in the shortterm rate and the standardized coefficient associated with the term spread is larger than the one associated with the output gap. However, inflation has no explanatory power, as it also occurs in the first regime. In sum, these estimation results are qualitatively similar to those obtained estimating the Markov switching VAR model (10). 


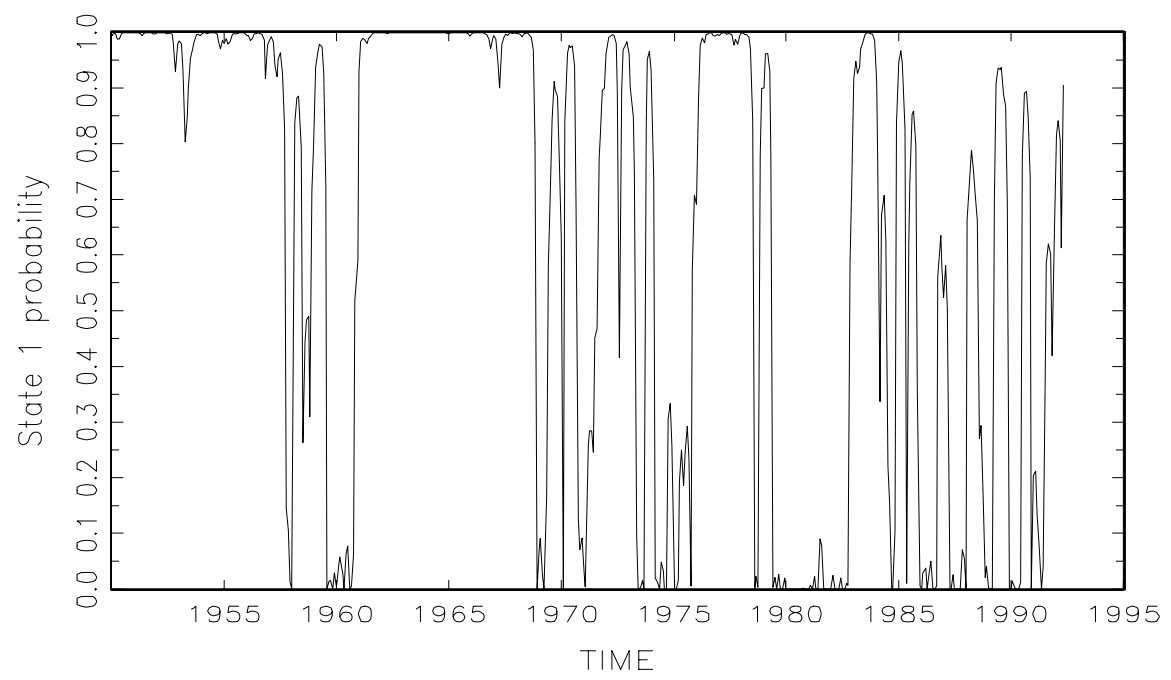

Figure 5: Short-term rate process (3)

Figures 5 and 6 show the allocation of time periods between regimes for equations (3) and (12) based on the smoothed probabilities using information over the whole sample of size $T$ (i.e., $\operatorname{prob}\left[s_{t}=1 \mid I_{T}\right]$ ), respectively. In spite of the fact that the output gap helps to explain the changes in the short rate, a comparison of Figures 5 and 6 clearly shows that the allocation of time periods between regimes does not depend on the inclusion of the output gap in the short-term rate process. 


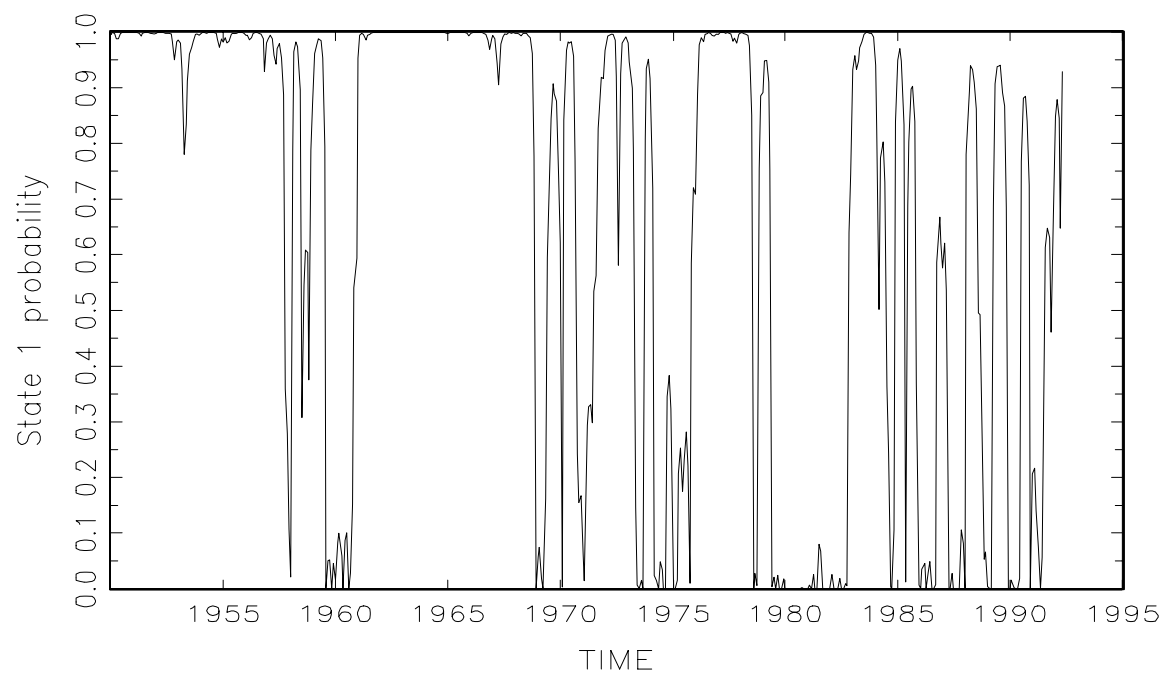

Figure 6: Short-term rate process (12) 


\section{References}

[1] Aït-Sahalia, Y. (1996) Testing continuous-time models of the spot interest rate, Review of Financial Studies 9, 385-426.

[2] Ang, A., and G. Bekaert (2002) Short rate non-linearities and regime switches, Journal of Economic Dynamics and Control 26, 1243-1274.

[3] Broze, L., and A. Szafarz (1991) The Econometric Analysis of NonUniqueness in Rational Expectations Models, North-Holland, New York.

[4] Campbell, John Y. (1995) Some Lessons from the Yield Curve, Journal of Economic Perspectives 9, 129-152.

[5] Estrella, A., and Frederic S. Mishkin (1997) "The predictive power of the term structure of interest rates in Europe and the United States: Implications for the European Central Bank," European Economic Review 41, 1375-1401.

[6] Evans, C.L., and D. Marshall (2001) Economic determinants of the nominal treasury yield curve, Federal Reserve Bank of Chicago working paper.

[7] Evans, M.D., and K.K. Lewis (1995) Do expected shifts in inflation affect estimates in the long-run Fisher relation?, Journal of Finance 50, 225-253.

[8] Farmer, R. (1991) The Lucas Critique, policy invariance and multiple equilibria, Review of Economics Studies 58, 321-332.

[9] Farmer, R. (1992) A comment on testing the Lucas Critique: a review, Econometric Reviews 11, 307-311.

[10] Favero, C., and D. Hendry (1992) Testing the Lucas Critique: a review, Econometric Reviews 11, 265-306.

[11] Fuller, W. (1976) Introduction to Statistical Time Series, Wiley \& Sons, New York.

[12] Gutiérrez, M.J., and J. Vázquez (2002) Present value models with feedback: Dynamic properties of alternative RE equilibria, Annales d'Economie et de Statistique 67/68, 131-154. 
[13] Lucas, R. (1976) Econometric policy evaluation: a critique, in The Phillips Curve and Labor Markets (Ed.) K. Brunner and A. Meltzer, The Carnegie-Rochester Conference Series on Public Policy, pp. 19-46.

[14] Hamilton, J.D. (1988) Rational-expectations econometric analysis of changes in regime. An investigation of the term structure of interest rates, Journal of Economic Dynamics and Control 13, 385-423.

[15] Hamilton, J.D. (1994) Time Series Analysis. Princeton University Press, New Jersey.

[16] Mankiw, N.G., and J.A. Miron (1986) The changing behavior of the term structure of interest rates. Quarterly Journal of Economics 101, $211-228$.

[17] McCallum, B.T. (1983) On non-uniqueness in RE models: an attempt at perspective, Journal of Monetary Economics 11, 139-168.

[18] McCallum, B.T. (1994) Monetary policy and the term structure of interest rates. NBER Working Paper, no. 4938.

[19] Mishkin, F.S. (1990) The information in the longer maturity term structure about future inflation, Quarterly Journal of Economics 105, 815-828.

[20] Salomon Brothers (1992) Analytical Record of Yields and Yield Spreads.

[21] Shiller, R.J. (1979) The volatility of long-term interest rates and expectations models of the term structure, Journal of Political Economy 87, 1190-1219.

[22] Sola, M., and J. Driffill, (1994) Testing the term structure of interest rates using a stationary vector autoregression with regime switching, Journal of Economic Dynamics and Control 18, 601-628.

[23] Taylor, John B. (1993) "Discretion versus policy rules in practice," Carnegie-Rochester Series on Public Policy 39, 195-214.

[24] Vázquez, J. (2002) Does the Lucas Critique applied during hyperinflation? Empirical evidence from four hyperinflationary episodes, Applied Economics 34, 1389-1397. 


\section{MATHEMATICAL WORKINGS}

Equations (3) and (4) form a bivariate system of difference equations. Using the undetermined coefficient method (McCallum (1983) among others) we begin by writing $R_{t}$ as a linear function of a minimal set of state variables: $r_{t}$ and a constant that is state dependant,

$$
R_{t}=\pi_{0}\left(s_{t}\right)+\pi_{1}\left(s_{t}\right) r_{t} .
$$

For appropriate real values of $\pi_{0}\left(s_{t}\right)$ and $\pi_{1}\left(s_{t}\right)$, the expectational variable $E_{t} R_{t+1}$ will then be given by

$$
\begin{aligned}
E_{t} R_{t+1}= & E_{t}\left(\pi_{0}\left(s_{t+1}\right)\right)+E_{t}\left(\pi_{1}\left(s_{t+1}\right) r_{t+1}\right)= \\
& E_{t}\left(\pi_{0}\left(s_{t+1}\right)\right)+E_{t}\left(\pi_{1}\left(s_{t+1}\right) \rho_{0}\left(s_{t+1}\right)\right)+ \\
& E_{t}\left[\pi_{1}\left(s_{t+1}\right) \rho_{1}\left(s_{t+1}\right)\left(\pi_{0}\left(s_{t}\right)+\pi_{1}\left(s_{t}\right) r_{t}\right)\right]+ \\
& E_{t}\left[\pi_{1}\left(s_{t+1}\right)\left(1-\rho_{1}\left(s_{t+1}\right)\right)\right] r_{t} .
\end{aligned}
$$

To evaluate the $\pi$ 's, we substitute (3), (5) and (??) into (4), which gives

$$
\begin{gathered}
\pi_{0}\left(s_{t}\right)+\pi_{1}\left(s_{t}\right) r_{t}=\delta E_{t}\left[\pi_{0}\left(s_{t+1}\right)+\pi_{1}\left(s_{t+1}\right) \rho_{0}\left(s_{t+1}\right)+\pi_{1}\left(s_{t+1}\right) \rho_{1}\left(s_{t+1}\right) \pi_{0}\left(s_{t}\right)\right]+ \\
\delta E_{t}\left[\pi_{1}\left(s_{t+1}\right)\left(\pi_{1}\left(s_{t}\right) \rho_{1}\left(s_{t+1}\right)+1-\rho_{1}\left(s_{t+1}\right)\right)\right] r_{t}+(1-\delta) r_{t}+c(1-\delta) .
\end{gathered}
$$

Recalling that $s_{t}$ belongs to the information set at time $t$, this equation implies identities in the constant term and $r_{t}$ for each state $s_{t}=1,2$ as follows:

$$
\begin{aligned}
& \pi_{0}(1)= \delta\left[p \pi_{0}(1)+(1-p) \pi_{0}(2)+p \pi_{1}(1) \rho_{0}(1)+(1-p) \pi_{1}(2) \rho_{0}(2)+\right. \\
&\left.\left(p \pi_{1}(1) \rho_{1}(1)+(1-p) \pi_{1}(2) \rho_{1}(2)\right) \pi_{0}(1)\right]+c(1-\delta) \\
& \pi_{0}(2)=\delta\left[q \pi_{0}(2)+(1-q) \pi_{0}(1)+q \pi_{1}(2) \rho_{0}(2)+(1-q) \pi_{1}(1) \rho_{0}(1)+\right.\left.\left(q \pi_{1}(2) \rho_{1}(2)+(1-q) \pi_{1}(1) \rho_{1}(1)\right) \pi_{0}(2)\right]+c(1-\delta), \\
& \pi_{1}(1)=\delta\left[\left(p \pi_{1}(1) \rho_{1}(1)+(1-p) \pi_{1}(2) \rho_{1}(2)\right) \pi_{1}(1)+p \pi_{1}(1)\left(1-\rho_{1}(1)\right)+\right. \\
&\left.(1-p) \pi_{1}(2)\left(1-\rho_{1}(2)\right)\right]+1-\delta \\
& \pi_{1}(2)=\delta\left[\left(q \pi_{1}(2) \rho_{1}(2)+(1-q) \pi_{1}(1) \rho_{1}(1)\right) \pi_{1}(2)+q \pi_{1}(2)\left(1-\rho_{1}(2)\right)+\right. \\
&\left.(1-q) \pi_{1}(1)\left(1-\rho_{1}(1)\right)\right]+1-\delta .
\end{aligned}
$$

After some simple, but tedious, algebra (a solver equation software makes things easier), one can show that there are four solutions to the system of equations (??) and that the equilibrium solution (6) is the only one satisfying McCallum's criterion. 